\title{
The Differential Effect of Two Types of Direct Written Corrective Feedback on Noticing and Uptake: Reformulation vs. Error Correction
}

\author{
MARÍA SANTOS \\ SONIA LÓPEZ-SERRANO \\ ROSA M. MANCHÓN* \\ University of Murcia
}

Received: 19 July 2010 / Accepted: 11 September 2010

\begin{abstract}
Framed in a cognitively-oriented strand of research on corrective feedback (CF) in SLA, the controlled threestage (composition/comparison-noticing/revision) study reported in this paper investigated the effects of two forms of direct CF (error correction and reformulation) on noticing and uptake, as evidenced in the written output produced by a group of 8 secondary school EFL learners. Noticing was operationalized as the amount of corrections noticed in the comparison stage of the writing task, whereas uptake was operationally defined as the type and amount of accurate revisions incorporated in the participants' revised versions of their original texts. Results support previous research findings on the positive effects of written CF on noticing and uptake, with a clear advantage of error correction over reformulation as far as uptake was concerned. Data also point to the existence of individual differences in the way EFL learners process and make use of CF in their writing. These findings are discussed from the perspective of the light they shed on the learning potential of CF in instructed SLA, and suggestions for future research are put forward.
\end{abstract}

KEYWORDS: Attention; Collaborative Writing; Corrective Feedback; EFL; Error Correction; Feedback; L2 Writing; Noticing; Reformulation.

\section{RESUMEN}

Enmarcado en la investigación de orden cognitivo sobre la corrección (“corrective feedback”), en este trabajo se investigó la incidencia de dos tipos de corrección escrita (corrección de errores y reformulación) en los procesos de detección (noticing) e incorporación (“uptake”). Ocho alumnos de inglés de Educción Secundaria participaron en un experimento que constó de tres etapas: redacción, comparación-detección y revisión. La detección se definió operacionalmente en términos del número de correcciones registradas por los alumnos durante la etapa de detección-comparación, mientras que la operacionalización del proceso de incorporación fue el tipo y cantidad de revisiones llevadas a cabo en la última etapa del experimento. Nuestros resultados confirman los hallazgos de la investigación previa sobre los efectos beneficiosos de la corrección de errores frente a la reformulación, especialmente en lo relativo a las revisiones de los textos escritos por los informantes. Los datos también indican la existencia de diferencias individuales en la forma en que los participantes procesaron e hicieron uso de la respuesta que recibieron a sus redacciones. Estos resultados se interpretan desde la perspectiva de la luz que arrojan sobre el potencial de aprendizaje que poseen las técnicas de corrección en el aprendizaje formal de segundas lenguas, al tiempo que se sugieren posibles líneas de trabajo para la futura investigación en el campo.

PALABRAS CLAVE: Atención, Escritura Colaborativa, Corrección, Inglés como Lengua Extranjera, Corrección de Errores, Respuesta al Escrito, Escritura en Segundas Lenguas, Detección, Reformulación.

*Address for correspondence: Rosa M. Manchón. Departamento de Filología Inglesa, Facultad de Letras, Campus de La Merced, 30071. Murcia, Spain. E-mail: manchon@um.es 


\section{INTRODUCTION}

The study to be reported in this article focuses on the effects of corrective feedback (CF) in promoting interlanguage development. As such, the study contributes to the overall aims of this special issue given that CF research "constitutes an area of inquiry that can connect theory, research and practice” (Sheen, 2010a:177).

Research on feedback, especially corrective feedback (CF), has attracted plenty of attention in both second language acquisition (SLA) research and second language (L2) writing studies. However, the research traditions on CF in these two fields have followed different paths in their theoretical and methodological orientations, with the result that they have developed almost independently from each other (see Ferris, 2010, for an updated account). The SLA CF research has been framed mainly in psycholinguistic and cognitive theories of SLA, and it has pursued to investigate the (short-term) effects of CF on acquisition. However, given its almost exclusive focus on "oral" CF, the way in which receiving and processing “written” CF feedback can aid L2 development has until recently been almost absent in the CF research agenda.

Despite the central stage position that feedback studies occupy in L2 writing research at large, the potential of CF for "acquisition” has not been a major focus of concern in L2 writing theorizing, empirical research or pedagogical discussions either. Instead, the relevant item in the L2 writing research agenda has been the investigation of "feedback-for-accuracy" issues, hence neglecting “feedback-for-acquisition” concerns (see Manchón, In press a). This is again understandable given that the bulk of L2 writing research has addressed the learningto-write dimension of writing, i.e. issues related to the manner in which L2 users develop writing skills and abilities (see Leki, Cumming \& Silva, 2008, for a recent comprehensive review). In contrast, the study of "feedback for acquisition" would be part of a slightly different research agenda, namely, a "writing-to-learn” agenda, whose focus would shift from investigating the way in which people learn to write, to the investigation of the manner in which writing (including both text generation activity and the processing of feedback) can aid interlanguage development. This state of affairs is nevertheless rapidly changing. A SLAoriented line of investigation, fully framed in cognitive views of language acquisition, has began to address writing-to-learn concerns (see Manchón, In press b, Forthcoming; Ortega, 2009). It is acknowledged that writing can represent an ideal scenario for the investigation of non-directed forms of noticing and focus on form (FonF) processes (given the self-initiated nature of writing problems) and, as such, it constitutes an ideal scenario for the investigation of self-initiated FonF processes. It thus represents a potential site for learning given that, as claimed by Williams (2001), "the effectiveness of FonF is ultimately determined by learner need" (pag. 175). This would justify the examination of those language use contexts in which "learners themselves choose to focus on formal aspects of the language" (Williams, 
2001:304), as is the case of writing. Similarly, it is acknowledged that the processing of feedback can engage learners in actions with potential learning effects, such as noticing and FonF. As neatly summarized by Sheen (2010a:175):

instead of viewing the goal of teaching writing as that of improving the learners' writing skills, practice in writing can be seen as one form of output that in conjunction with CF, can facilitate interlanguage development. In other words, instruction that incorporates written CF constitutes a technique to draw L2 learners' attention to linguistic forms in their own output and thereby facilitate acquisition.

The study to be reported in this article is framed in this writing-to-learn line of research within CF studies and it is part of wider programme of research currently under way at the University of Murcia in which we are investigating the learning potential of L2 writing (see Manchón \& Roc, Forthcoming) . More precisely, the study to be reported in this article, which is exploratory in nature, intends to add to the existing research on the effects of different forms of direct corrective feedback by providing empirical data derived from a population (adolescent, secondary school students) that has not featured prominently in previous studies (but see studies on reformulation by Swin and collegues, cf. Lapkin, Swain \& Smith, 2002; Swain \& Lapkin, 2002; Tocalli-Beller \& Swain, 2005; Watanabe \& Swain, 2007), a new acquisitional context (a foreign language setting) and slightly modified experimental conditions (regarding time on task and depth of processing of feedback) from those of previous research. A review of this previous empirical work on written CF feedback follows as the necessary background to our own empirical study.

\section{I.1 Review of empirical research on written CF}

A central tenet of the original formulation of the Output Hypotheis (cf. Swain, 1985, 1995) was that the noticing function associated with the production of challenging output entailed a consciousness-raising function that could result in prompting learners to (i) look for ways to fill their noticed gaps, and/or (ii) engage in more focused attention to incoming input. A substantial number of studies have shed light, first, on the role of individual or collaborative output practice in processing subsequent incoming input, and, second, on the effects of such linguistic processing on learning (see Manchón, In press, a, Forthcoming, a for a review).

For our present purposes, the relevant line of research is the one in which scholars have explored the manner in which providing learners with input/feedback and prompting them to process such input (either individually or collaboratively) has any effects on learning. Accordingly, the participants in these studies were asked to produce a text, and they were then provided with some kind of input or feedback whose effect on learning was assessed. Learning has been operationalized in two main ways: performance of language test pre- and post-treatment, and/or differences between the features of the text produced before and after the provision of input/feedback. The type of input/feedback provided have included (a) 
models (Hanaoka, 2007), (b) provision of feedback on the students' writing and reflection (languaging) on it (Suzuki, 2008), and (c) engagement in tutorial sessions (Nassaji \& Swain, 2000), together with (d) the provision of a whole range of direct and indirect CF options. Regarding the latter, some studies have investigated the effect of just one type of feedback, most notably the effects of reformulation (cf. Adams, 2003; Lapkin, Swain \& Smith, 2002; Qi \& Lapkin, 2001; Swain \& Lapkin, 2002; Tocalli-Beller \& Swain, 2005; Watanabe \& Swain, 2007), a technique whereby the participants' texts are rewritten to make them sound as native-like as possible in terms of grammar and lexis while preserving their original meaning (Thornbury, 1997). Some other studies have compared two types of feedback, such as two forms of direct corrective feedback (reformulation and error correction, Sachs \& Polio, 2007), self-correction and CF (Lázaro, 2009), a combination of direct (reformulation) and indirect (editing) CF (Storch \&Wigglesworth, 2010), or oral/written feedback or focused and/or unfocused feedback with or without metalinguistic explanations (Bitchener 2008; Bitchener \& Knoch, 2008; Ellis et al 2008; Sheen, 2007, 2010).

Seen from another perspective, these CF studies fall into two general categories according to whether the feedback provided (regardless of its type) was focused or unfocused, i.e. whether or not CF targeted specific linguistic forms. Focused CF studies (Bitchener 2008; Bitchener \& Knoch, 2008; Ellis et al 2008; Sheen, 2007, 2010a) have all investigated the effect of CF on the acquisition of English articles and the general conclusion is that CF has positive short-term effects on learning. This research also shows that these learning effects appear to be mediated by two variables: the explicitness of the feedback received (cf. Sheen, 2010b) and the learners' depth of processing of the CF (cf. Bitchener, 2008; Bitchener \& Knoch, 2008). Regarding the latter, more positive effects have been found to result from the learner's engagement in deeper processing than just noticing differences between their own writing and the feedback they receive on it at the level of simple detection. Nevertheless, these findings from focused feedback studies have to be taken with caution because, as recently noted by Xu (2009) and Ferris (2010), only a limited number or errors related to a restricted range of linguistic forms have been investigated so far. Therefore, it is still an empirical question whether or not the observed benefits of CF apply to the acquisition of more complex target features and structures.

In contrast to focused CF studies, unfocused CF studies (cf. cf. Adams, 2003; Qi \& Lapkin, 2001; Sachs \& Polio, 2007; Storch \&Wigglesworth, 2010; Swain \& Lapkin, 2002; Tocalli-Beller \& Swain, 2005; Watanabe \& Swain, 2007) have not targeted a particular set of linguistic features in the CF provided. Collectively considered, this research has found that the output practice promoted in collaborative writing fosters noticing processes, especially noticing the hole (while engaged in text-generation activity) and noticing the gap (via the 
analysis of the CF received on one's own writing). It is also a finding from this research that this noticing activity results in short-term effects on learning (as measured by incorporation of corrections in post-tests or revised texts), this being specially the case when deeper processing of CF than simple detection was promoted. As we will see later, in the study to be reported below measures were taken to foster the participants' deep engagement with the two forms of feedback implemented in the treatment conditions. Of special theoretical and pedagogical relevance is also the finding that more accurate texts were produced when provided with error correction than when provided with reformulations (cf. Sachs \& Polio, 2007). However, these findings on the benefits of error correction over reformulation have to be taken with caution given the scant research on the topic and the focus on adult, second language, university students of high-intermediateL2 proficiency (Sachs \& Polio, 2007). Hence, the results may not be generalizable across learner populations and acquisitional contexts.

In short, there are still many open questions regarding which type of CF elicits more attention to form, which type of feedback leads to more (durable) uptake, or which taskrelated variables or learner-related variables may affect the learner's processing of CF and the effects of various forms CF on noticing and uptake.

\section{I.2 The present study}

Building on the work of previous researchers on the effects of various forms of CF, the study to be reported in this article attempted to expand the empirical data basis on the learning potential of CF with its focus on the processing of two types of direct CF (reformulation and error correction) by adolescent, secondary-school English foreign language learners of English of an intermediate level of L2 proficiency. Bearing in mind previous research findings and suggestions for further research avenues to explore, we designed a controlled three-stage (composition/comparison-noticing/revision) study in which the comparisonnoticing stage attempted to engage our participants in deeper processing of feedback than mere detection of differences between their own output and the feedback received on it. In addition, we also designed the study in a manner that our participants would not be constrained by time consideration in the processing of the CF provided, a decision taken on the basis of Sachs and Polio's (2007) suggestions regarding the relevance of expanding time on task to facilitate the processing of feedback (their participants were allowed only 15 minutes to process the CF received).

In view of these considerations, the study was guided by the following research questions:

1. Are there any quantitative differences in secondary school students' noticing processes when they receive CF in the form of either reformulation or in the form of error correction? 
2. Does the linguistic accuracy of their revisions vary when they are provided with CF in the form of reformulation or in the form of error correction?

3. What type of revisions do students incorporate in their texts when they are provided with $\mathrm{CF}$ in the form of reformulation or in the form of error correction?

\section{METHOD}

\section{II.1 Participants}

Eight Spanish high school students, 4 males and 4 females, aged 15 or 16, took part in the study. All the students were working towards their International Baccalaureate Diploma. The participants had been learning English for a total of 7 years and their level of English was B1 according to the Common European Framework of Reference.

For the purpose of the study, the students were distributed by the teacher (one of the researchers) in pairs. The same two students were paired up for both the reformulation (REF) and the error correction (EC) conditions. Previous research has shown that the language learning afforded by collaborative writing is partially dependent on the nature of the interaction engaged in by the writing partners, the most useful pattern being "collaboration" (see Storch, 2002a, b, 2007). Bearing these findings in mind, pairs were formed according to the level of equality and mutuality observed in their daily behavior in class, something that could be easily assessed as their teacher was one of the researchers. In addition, an attempt was made to balance gender in the different pairs and we took into account the students'

Following these criteria, four pairs were formed. They were made up of one female and one male student each, who got along well and who were considered to have a high level of mutuality and equality, that is, they were expected to be collaborative in their interaction during task performance.

\section{II.2 Tasks and procedures}

\section{II.2.1 Research overview}

A repeated measures design was implemented. Participants attended six different sessions over a period of two weeks, three sessions for each experimental condition (i.e. REF and EC conditions). As shown in Table 1, these sessions consisted of collaborative writing (Session 1), collaborative comparison-noticing (Session 2) and individual revision (Session 3). The sessions took place on alternative days (Monday, Wednesday, and Friday, respectively) over 
two weeks, with the reformulation preceding the error correction condition. Due to practical reason it was not possible to counteract the order of tasks and this is acknowledge as a limitation of the study. Possible task effects may have resulted, as noted in a later section.

\begin{tabular}{|c|c|c|c|c|}
\hline Week & $\begin{array}{l}\text { Experimental } \\
\text { Condition }\end{array}$ & $\begin{array}{l}\text { Monday } \\
\text { Session 1: } \\
\text { Collaborative writing } \\
\text { (50') }\end{array}$ & $\begin{array}{l}\text { Wednesday } \\
\text { Session 2: Noticing } \\
(50 \text { ') }\end{array}$ & $\begin{array}{l}\text { Friday } \\
\text { Session 3: Individual } \\
\text { revision (50') }\end{array}$ \\
\hline Week 1 & REFORMULATION & $\begin{array}{l}\text { Collaborative writing } \\
\text { of a story based on a } \\
\text { picture prompt (Text } 1 \text { ) }\end{array}$ & $\begin{array}{lr}\text { Comparison } & \text { of } \\
\text { collaborative } & \text { written } \\
\text { texts with } & \text { a } \\
\text { reformulated } & \text { version } \\
(\mathrm{RF}) & \end{array}$ & $\begin{array}{l}\text { Individual revision of } \\
\text { Text } 1 .\end{array}$ \\
\hline Week 2 & $\begin{array}{l}\text { ERROR } \\
\text { CORRECTION }\end{array}$ & $\begin{array}{l}\text { Collaborative writing } \\
\text { of a story based on a } \\
\text { picture prompt (Text } \\
\text { 1b) }\end{array}$ & $\begin{array}{l}\text { Comparison of } \\
\text { collaborative written } \\
\text { texts with a corrected } \\
\text { version (EC). }\end{array}$ & $\begin{array}{l}\text { Individual revision of } \\
\text { Text } 1 \text { b. }\end{array}$ \\
\hline
\end{tabular}

Table 1. Three-day sequence of the two experimental conditions.

\section{II.2.2 Implementation}

Following previous research on the topic, participants in the two experimental conditions were instructed to work with the partners in the writing of a story following a prompt consisting of six pictures that formed a narrative. The students were encouraged to negotiate how to best write the story from the pictures and to interact in English at all times. They were allotted as much time as needed within the class period and all the pairs finished the task within the 50 minutes of class time.

\section{Reformulation condition}

Following the students' writing session, the teacher-researcher made copies of the students' original texts and reformulated each story to make it sound native-like (in terms of both accuracy and idiomaticity) while keeping their original meaning intact. Grammar errors (such as verb formation, punctuation, subject-verb agreement and choice of preposition) were corrected and inaccurate vocabulary choices and inappropriate use of cohesive devices were revised where deemed necessary. As an example:

Original text: He pulled out his clothes and he left them near the costline.

Reformulated version: He took off his clothes and left them near the seaside.

The noticing session (Session 2) took place two days later. Our participants were handed the picture prompt, their original text, the teacher-researcher's reformulated version of 
it, and a noticing table to fill in during the comparison of their text with the reformulated version. We opted for a form of guided noticing (the noticing table) in view of previous findings on the relationship between depth of processing of noticing and learning outcomes. In particular, we took into account Qi and Lapkin's (2001) claim that noticing with understanding has more positive effects than noticing without understanding or "noticing for no articulated reason" (pag. 71). We tried to promote this noticing with understanding by asking our participants to fill in a table in which they had to (i) annotate their errors and their corresponding reformulation (ii) decide which type of error it was (grammar, lexis or discourse), and, (iii) state whether or not they accepted the reformulation, as well as provide reasons for not incorporating the reformulation, when applicable. Given previous suggestions on the relevance of allowing plenty of time for students to engage in noticing processes (Sachs \& Polio, 2007), our participants were given 50 minutes, and all of them finished within this time limit.

Session 3 took place two days later. As the focus of the study was the effect of CF rather than on collaborative writing, the rewriting session was performed indiviadually, as was also the case of previous research (cf. Polio \& Sachs, 2007). The students sat individually and the teacher-researcher handed them the picture prompt, their original story and a blank sheet of paper and asked them to rewrite the story as close as possible to the accepted reformulated version they had worked on in Session 2. The students were not allowed to ask any questions or to communicate with their peers, and they were given a maximum of 45 minutes to complete the assignment. All the students completed the task during this time limit.

\section{Error correction condition}

The Error Correction treatment sessions took place during the second week and the procedure followed was exactly the same as the one described for the Reformulation condition. In Session 1 students again collaboratively wrote a text based on a picture prompt. The teacherresearcher collected the texts and she corrected students' errors (related to grammar, vocabulary and textual cohesion) in a copied version of students' original texts, as shown in the following example:

Original text: It was an excited afternoon.

exciting

Error correction version: It was an excited afternoon. 
Following the same procedure as in the Reformulation condition, in Session 2 the students in the four pairs had to compare their original texts written in Session 1 with the corrected version provided by the teacher, and then fill in the same noticing table as in the Reformulation condition. In Session 3 they were instructed to individually rewrite their original texts bearing in mind the corrected errors they had noticed in Session 2. Time conditions were the same as those in the Reformulation treatment.

Once the two treatments had been completed, the students were individually interviewed in order to explore their views on both types of feedback. This interview data was treated in this study solely as a secondary data source to be used in making sense of the primary data.

\section{II.3. Data Analysis}

The primary data for the study consisted of the texts written in pairs in the two treatment conditions (8 collaborative texts), the noticing tables filled in Session 2 in both conditions (8 tables), and the texts written individually in Session 3 after receiving reformulation or error correction feedback (16 individual texts). In view of the research questions guiding the study, three types of analyses were conducted on these various data sources.

First, for the analysis of noticing processes (Research Question $n^{\circ} 1$ ), the operational definition of noticing was the number of reformulations or error corrections identified by students in Session 2 as manifested in the noticing tables completed in pairs. Absolute frequencies of noticing were computed for each pair in each of the experimental conditions. Thus, based on the noticing tables, instances of noticing were computed by noting the errors in the participants' original texts and whether or not the reformulation or correction had been included in the noticing table filled in collaboratively in Session 2.

Uptake was operationally defined as both the type and the amount of accurate revisions incorporated in the participants' revised versions of their original texts. For the quantitative analysis (Research Question no. 2) we first computed the accuracy (or lack of) of the revisions of each noticed item by each pair and each participant within the pairs. In addition, to gain deeper insight into the accuracy of students' revised texts, the revisions in the participants' texts were also analyzed in terms of T-units. A T-Unit was conceptualized as one main clause plus whatever subordinate clauses happen to be attached to or embedded within it (Hunt, 1996). T-units were first identified in the original texts written in pairs in Stage 1, and then compared to the revised texts written individually in Stage 3. Following Sachs and Polio (2007), as shown in Table 2, the T-Units in the rewritten texts were coded for changes in 
accuracy, that is, any observable correction or partial change in the direction of the feedback provided according to the following categories:

- CC (completely changed), if all errors had been corrected.

- PC (partially changed), if at least one error had been changed in the direction of the feedback provided.

- UC (completely unchanged), if the T-Unit had all the errors shown in the original version.

- NA (non applicable), if the original T-unit had no errors.

\begin{tabular}{|l|l|l|}
\hline TEXT & T-UNIT & CODE \\
\hline Original text & He pulled out his clothes and he left them near the costline. & \\
\hline Correction & He took off his clothes and left them near the seaside. & \\
\hline Revision S5 & He took off his clothes and he left them near the sealine. & PC \\
\hline Revision S6 & He took off his clothes and he left them near the seaside. & CC \\
\hline
\end{tabular}

Table 2: Example of coding of T-Units

Two researchers individually coded the T-units in each text. The intercoder agreement obtained was 94\%, and then any disagreement was resolved by means of conferencing. For every participant, the total number of T-Units in the revised version of the original writing that showed changes in accuracy (coded PC or CC) was divided by the total number of TUnits that contained errors in the original version. The T-Units coded as NA were not taken into consideration for the analysis.

Finally, the qualitative analysis of uptake was concerned with the nature of the errors whose revisions were incorporated in the individually rewritten texts (Research Question $\mathrm{n}^{\circ}$. 3). For this coding, we took Qi and Lapkin's (2001) categories as a basis and we refined them to fit our data. Following this procedure we obtained three categories:

- Form (verb morphology, verb formation, subject-verb agreement, preposition use, spelling)

- Lexis (choice of incorrect or inappropriate word or expression)

- Discourse (logical sequencing of the text: cohesive devices, reference, repetition, etc.)

Two researchers coded the data independently. The inter-rater agreement for the coding of errors in both conditions was 92\%, (based on simple percentage agreement). Any disagreement was resolved by means of conferencing until consensus was reached. 
Due to the small sample size, the data were analyzed mainly in terms of descriptive statistics. When necessary, non-parametric Wilcoxon signed ranks tests were conducted to check whether there were significant differences between both conditions.

\section{RESULTS}

The analysis of results that follows will be structured according to the research questions guiding the study.

III.1. Research Question 1: Are there any quantitative differences in secondary school students' noticing processes when they receive $C F$ in the form of either reformulation or in the form of error correction?

Our first research question asked whether there were any differences could be observed in the amount of noticing fostered by reformulation (REF) and the error correction (EC) conditions. Data show, first, that the participants received more reformulations than error corrections, and, second, that more variation among pairs could be observed in the amount of CF received in the EC than in the REF condition: as depicted in Tables 1 and 2, the teacherresearcher provided students with 52 reformulations $(M=13)$ and 29 error corrections $(M=$ 7.25). However, whereas the amount of reformulations provided remained almost the same across pairs, there was a wider variation in the amount of corrections provided in the EC condition.

\begin{tabular}{|c|c|c|c|}
\hline \multicolumn{4}{|c|}{ REFORMULATION } \\
\hline & $\begin{array}{l}\mathrm{N}^{\circ} \text { of } \\
\text { reformulations } \\
\text { provided }\end{array}$ & $\begin{array}{l}\mathrm{N}^{\circ} \text { of } \\
\text { reformulations } \\
\text { noticed }\end{array}$ & $\%$ \\
\hline $\begin{array}{l}\mathrm{S}-1 \\
\mathrm{~S}-2\end{array}$ & 12 & 12 & 100 \\
\hline $\begin{array}{l}\text { S-3 } \\
\text { S-4 }\end{array}$ & 14 & 14 & 100 \\
\hline $\begin{array}{l}\text { S-5 } \\
\text { S-6 }\end{array}$ & 12 & 12 & 100 \\
\hline $\begin{array}{l}\text { S-7 } \\
\text { S-8 }\end{array}$ & 14 & 14 & 100 \\
\hline
\end{tabular}

Table 3: Noticing in the reformulation condition 


\begin{tabular}{|c|c|c|c|}
\hline \multicolumn{4}{|c|}{ ERROR CORRECTION } \\
\hline & $\begin{array}{l}\mathrm{N}^{\mathrm{o}} \text { of error } \\
\text { corrections } \\
\text { provided }\end{array}$ & $\begin{array}{l}\mathrm{N}^{\mathrm{o}} \text { of error } \\
\text { corrections } \\
\text { noticed }\end{array}$ & $\%$ \\
\hline $\begin{array}{l}\mathrm{S}-1 \\
\mathrm{~S}-2\end{array}$ & 6 & 6 & 100 \\
\hline $\begin{array}{l}\mathrm{S}-3 \\
\mathrm{~S}-4\end{array}$ & 4 & 4 & 100 \\
\hline $\begin{array}{l}\text { S-5 } \\
\text { S-6 }\end{array}$ & 10 & 10 & 100 \\
\hline $\begin{array}{l}\text { S-7 } \\
\text { S-8 }\end{array}$ & 9 & 9 & 100 \\
\hline
\end{tabular}

Table 4: Noticing in the Error Correction Condition

Despite these differences between the two conditions and across pairs, as shown in Tables 3 and 4, the two forms of direct CF provided in the study did not affect the participants' amount of noticing: our participants were able to notice all the corrections that they received when their texts were reformulated and when they received error correction on their original texts.

\section{III.2 Research Question 2: Does the linguistic accuracy of their revisions vary when they are provided with $C F$ in the form of reformulation or in the form of error correction?}

Our second research question was concerned with the uptake that resulted from the two experimental conditions. As mentioned earlier, two types of analyses were conducted. We first computed the percentage of individual errors accurately corrected in the revised version, whereas the second analysis considered accuracy in terms of T-Units.

\section{III.2.1 Accuracy of revised errors}

In contrast to the similarity in noticing behaviour previously mentioned, the two experimental conditions resulted in differences in uptake (see Table 5), with an advantage of the EC condition (83\% errors corrected) over the REF condition (53.51\%). A Wilcoxon signed rank test showed that these differences were statistically significant $(\mathrm{Z}=-2.380 ; p=.017)$. 


\begin{tabular}{|l|l|l|}
\cline { 2 - 3 } \multicolumn{1}{c|}{} & Reformulation & Error Correction \\
\hline M. & 63.51 & 83.31 \\
\hline s.d. & 19.72 & 17.70 \\
\hline Max & 92.85 & 100 \\
\hline Min. & 35.71 & 50 \\
\hline
\end{tabular}

Table 5: Uptake in the Reformulation and Error Correction Conditions (Individual Errors).

Our data further show the existence of individual differences, as shown in the data depicted in Figure 1. With the exception of S2, all the participants produced more accurate revisions in the EC condition. Individual differences were observed in the uptake that resulted in each and across conditions. Thus, 3 students (S1, S3 and S4) corrected all the errors in their original texts when provided with EC, and they showed the highest level of uptake in the REF condition. The rest of participants' uptake in the EC condition ranged from 50\% to $90 \%$ and from $40 \%$ to $90 \%$ in the REF condition.

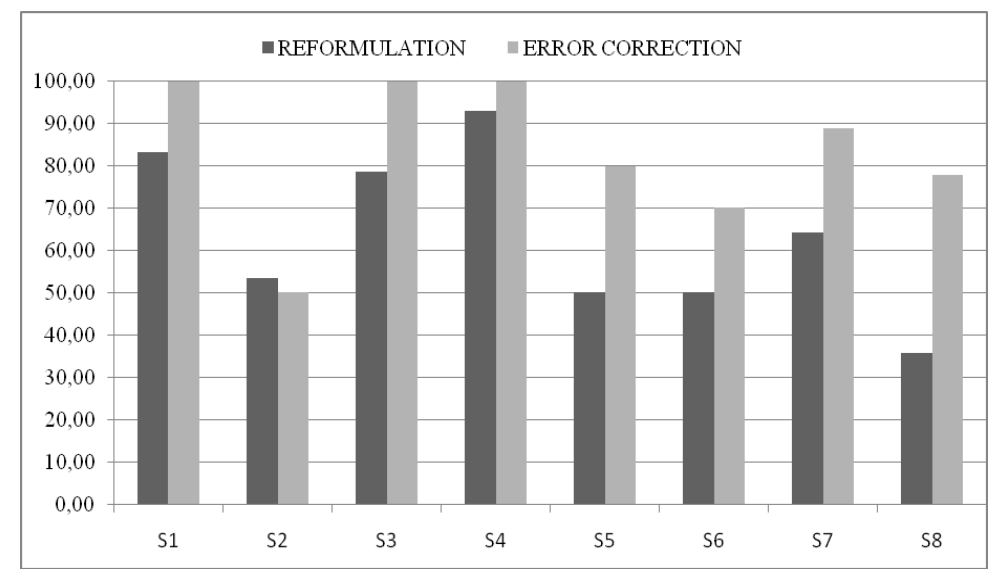

Figure 1. Individual students' uptake in the two experimental conditions (Individual Errors)

\section{III.2.1. Accuracy of revised T-units}

Similar uptake results (in global terms and also regarding inter-individual differences) were obtained when T-Units were analyzed. As can be seen in Table 6, our participants produced slightly more accurate texts in the EC condition than in the REF condition $(91.66 \%$ and 
8415\%, respectively), although these differences were not statistically significant $(Z=-.944$; $p=.345)$.

\begin{tabular}{|l|l|l|}
\hline & Reformulation & Error Correction \\
\hline M. & 84.15 & 91.66 \\
\hline s.d. & 15.98 & 17.81 \\
\hline Max. & 100 & 100 \\
\hline Min. & 62.5 & 50 \\
\hline
\end{tabular}

Table 6: Uptake in the Reformulation and Error Correction Conditions (T-Units).

In terms of individual students, as can be seen in Figure 2, with the exception of one participant (S2, whose uptake was also different from the rest in terms of individual errors), the error correction condition prompted changes in accuracy in all the T-units that originally contained errors. However, individual differences were observed: 3 participants (S1, S3 and S4, the same participants that showed higher levels of uptake as far as individual errors were concerned) showed $100 \%$ of uptake in both conditions, and 4 participants (S5, S6, S7 and S8, who howed higher levels of uptake in the EC condition in terms of corrections of individual errors) produced more accurate revisions in the reformulation condition.

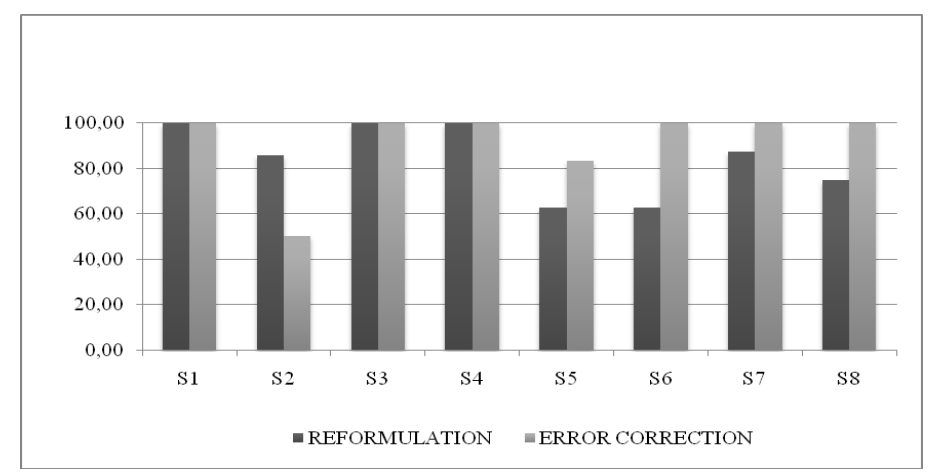

Figure 2. Individual students’ uptake in the two experimental conditions (T-Units)

Taken these two analyses together, the answer to our second research question is that in the EC condition prompted more accurate revisions in terms of both T-units and individual errors, this second measure showing statistically significant differences between both treatments. Despite these general tendencies, our data may also be taken to indicate that L2 
writers may benefit differentially from different types of direct CF, a prediction that needs further empirical confirmation given our small sample size.

\section{III.3. Research Question 3: What type of revisions do students incorporate in their revisions when provided with $C F$ in the form of reformulation or in the form of error correction?}

In order to gain a deeper understanding of the effects on uptake of the two treatments, we explored what kind of error revisions students incorporated more frequently in the two experimental conditions.

\begin{tabular}{|c|c|c|c|c|c|c|c|c|c|c|}
\hline \multirow{3}{*}{ Pair } & \multicolumn{10}{|c|}{ REFORMULATION } \\
\hline & \multirow{2}{*}{ Student } & \multicolumn{3}{|l|}{ FORM } & \multicolumn{3}{|l|}{ LEXIS } & \multicolumn{3}{|c|}{ DISCOURSE } \\
\hline & & Noticed & Incorp. & $(\%)$ & Noticed & Incorp. & $(\%)$ & Noticed & Incorp. & (\%) \\
\hline \multirow{2}{*}{ P-1 } & S-1 & 3 & 2 & 66.66 & 6 & 5 & 83.33 & 3 & 3 & 100 \\
\hline & $\mathrm{S}-2$ & 3 & 2 & 66.66 & 6 & 3 & 50 & 3 & 1 & 33.30 \\
\hline \multirow{2}{*}{ P-2 } & S-3 & 3 & 2 & 66.66 & 6 & 5 & 83.33 & 5 & 4 & 80 \\
\hline & S-4 & 3 & 3 & 100 & 6 & 6 & 100 & 5 & 4 & 80 \\
\hline \multirow{2}{*}{ P-3 } & S-5 & 2 & 2 & 100 & 5 & 2 & 40 & 4 & 0 & 0 \\
\hline & S-6 & 2 & 1 & 50 & 5 & 4 & 80 & 4 & 2 & 50 \\
\hline \multirow{3}{*}{ P-4 } & S-7 & 2 & 1 & 50 & 6 & 6 & 100 & 6 & 3 & 50 \\
\hline & S-8 & 2 & 0 & 0 & 6 & 4 & 66.66 & 6 & 2 & 33.33 \\
\hline & & 20 & 13 & $M=62.5$ & 46 & 35 & $M=75.42$ & 36 & 19 & $M=53$ \\
\hline
\end{tabular}

Table 7: Uptake in the Reformulation Condition (Type of Revisions)

As shown in Table 7 and Figure 3, students were able to incorporate more lexis reformulations (75.42\%) than form (62.5\%) or discourse (53\%) reformulations in their revised texts, even considering that the number of lexis REFs provided was much higher than those REFs in the other two categories. In addition, while our participants incorporated between $40 \%$ and $100 \%$ of the lexis-related reformulations, the other categories prompted more individual variation, since incorporations ranged from 0 to $100 \%$, this being specially the case in the discourse category.

In contrast to the reformulation condition, when provided with error corrections (Table 8 and Figure 3) students incorporated fairly similar amounts of revisions inhe three categories identified (form $M=85.71 \%$; lexis $M=87.5 \%$; discourse $M=87.5 \%$ ). 


\begin{tabular}{|c|c|c|c|c|c|c|c|c|c|c|}
\hline \multirow{3}{*}{ Pair } & \multicolumn{10}{|c|}{ ERROR CORRECTION } \\
\hline & \multirow{2}{*}{ Student } & \multicolumn{3}{|l|}{ FORM } & \multicolumn{3}{|l|}{ LEXIS } & \multicolumn{3}{|c|}{ DISCOURSE } \\
\hline & & Noticed & Incorp. & (\%) & Noticed & Incorp. & (\%) & Noticed & Incorp. & $(\%)$ \\
\hline \multirow{2}{*}{ P-1 } & S-1 & 1 & 1 & 100 & 3 & 2 & 66.66 & 2 & 2 & 100 \\
\hline & S-2 & 1 & 1 & 100 & 3 & 1 & 33.33 & 2 & 1 & 50 \\
\hline \multirow{2}{*}{ P-2 } & S-3 & 2 & 2 & 100 & 2 & 2 & 100 & NA & NA & \\
\hline & S-4 & 2 & 2 & 100 & 2 & 2 & 100 & NA & NA & \\
\hline \multirow{2}{*}{ P-3 } & S-5 & 7 & 5 & 71.42 & 2 & 2 & 100 & 1 & 1 & 100 \\
\hline & S-6 & 7 & 4 & 57.14 & 2 & 2 & 100 & 1 & 1 & 100 \\
\hline \multirow{3}{*}{ P-4 } & S-7 & 7 & 6 & 85.71 & 2 & 2 & 100 & NA & NA & \\
\hline & S-8 & 7 & 5 & 71.42 & 2 & 2 & 100 & NA & NA & \\
\hline & & 34 & 26 & $M=85.71$ & 18 & 15 & $M=87.5$ & 6 & 5 & $M=87.5$ \\
\hline
\end{tabular}

Table 8: Uptake in the Error Correction Condition (Type of Revisions)

In sum, as graphically depicted in Figure 3, the EC condition led to similar amounts of incorporations of the different types of error revisions. In contrast, when students were given reformulated versions of their texts, they tended to incorporate more revisions concerning vocabulary and they found it more difficult to include reformulations related to discourse issues.

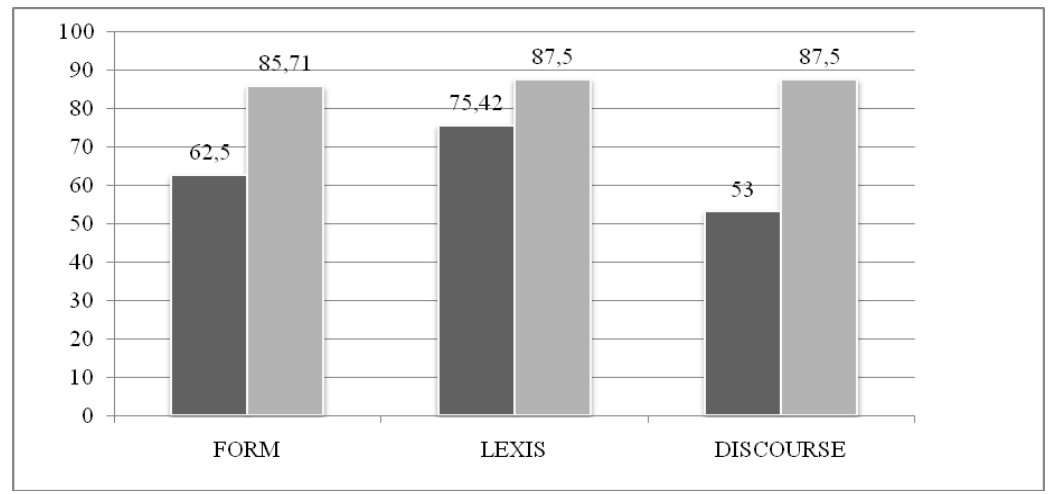

Figure 3. Nature of revised errors in both conditions.

\section{DISCUSSION}

This study was set up to investigate the effects of two types of CF on the revisions incorporated in the revised version of a previously produced text. Four main sets of findings emerged from the data obtained: (i) the lack of influence of treatment conditions on noticing, 
(ii) the greater uptake observed in the EC condition, (iii) the greater uptake as far as lexis was concerned in the reformulation condition vs. the similar uptake of lexical and grammatical uptake in the EC condition, and (iv) the individual differences observed in uptake. In what follows these four sets of findings will be discussed with respect to previous cognitivelyoriented research on the effects of CF on acquisition, and also with respect to what they may indicate in terms of relevant items for the future research agenda.

\section{IV.1 Treatment conditions and noticing}

The two forms of direct corrective feedback provided in the two treatment conditions did not result in quantitative differences in noticing behaviour, at least as operationalized in the present study. It is also worth mentioning that the participants in the present study were able to notice all the corrections that they received on their writing, regardless of treatment conditions or amount of corrections they were provided with.

Various possible explanations for these findings can be suggested. First, the participants' stage of interlanguage development may have facilitated their readiness to notice the feedback received, interlanguage development being a learner-related variable that has been emphasized in previous accounts of the relationship between feedback and noticing (cf. Hanaoka, 2006; Sachs \& Polio, 2007). Second, the fact that the noticing stage was performed collaboratively may have also played a role given previous tenets on the positive effects of collaboration on noticing (cf Storch, 2009; Swain, 2006; Swain \& Lapkin, 2002), and specially of the advantages of the metatalk associated with collaborative writing. This metatalk is thought to offer more favourable conditions for deeper levels of noticing at the level of understanding, as suggested in the noticing literature (cf. cf. Leow 2000; Robinson 1995; Rosa \& O’Neill 1999; Schmidt, 1990, 1993, 2001; Tomlin \& Villa, 1994; Toth 2006). In this respect, our data may also be interpreted as further support for the claim that the combination of speaking and writing that characterizes collaborative writing tasks can be taken to be more powerful in promoting FonF than the oral production mode alone present in oral task performance (cf. Adams \& Ross-Feldman 2008; Niu, 2009; Storch 2001; Swain 1998; Swain \& Lakpin 1998). However, these observations remain purely speculative as our study did not include a control group who performed the task individually and/or in the oral modality.

Task instructions may have also influenced our results. In this respect, the fact that the participants were well aware that they were in the midst of a process in the sense that they needed the feedback to revise their texts during the rewriting session might explain their attentiveness during the noticing session, perhaps in an attempt to memorize reformulations or 
corrections for the rewriting session, such memorization being a strategy mentioned in previous studies (cf. Hanaoka 2007, Sachs \& Polio, 2007).

Two further characteristics of the two treatment conditions may explain the noticing results obtained. These relate to both time on task and the guided nature of the noticing stage. As mentioned in the introductory section, in an attempt to advance in the exploration of potential variables influencing the processing of feedback, our participants were allowed to spend as much time as 50 minutes comparing their texts to the feedback provided and discussing the differences between them (in contrast to the time constrains imposed in previous studies, cf. Sachs \& Polio, 2007). This extra time may have neutralized potential differences in noticing behaviour in the two treatment conditions, which may have resulted from, first, the greater amount of corrections provided in the REF treatment, and, second, the very nature of reformulations, which makes this type of feedback less visually salient and explicit than error corrections. In fact, the degree of explicitness of the feedback provided to learners has been claimed to constitute the "pivotal factor" in making feedback beneficial for learners (Sheen, 2010b: 226).

Finally, the guided noticing implemented in the present research (together with the issue of time on task mentioned earlier), can be adduced as a further reason for the lack of influence of treatment conditions. Nevertheless, these findings would need further empirical confirmation in future research comparing guided and unguided noticing after receiving unfocused CF.

\section{IV.2 Treatment conditions and uptake: number of revisions}

The second main finding of our research relates to the greater uptake observed in the EC condition, thus supporting previous findings on the advantage of EC over reformulation. Our results show that the EC condition prompted more accurate revisions in terms of both Tunits and corrections of specific errors. This finding can be taken as further support of the advantages of EC over REF observed by Sachs and Polio (2007) in their study of university students in a second language contexts. According to our data, such an advantage also applies to adolescent, secondary-school students in a foreign language context.

This finding was further supported by the data obtained in the post-task interviews conducted, which, as noted above were used only as secondary data in this study. Our participants manifested that their preference for error correction over reformulation given that error corrections were considered easier to detect and to incorporate into their texts. They also pointed out that reformulations were completely new to them as a form of feedback and, therefore, they considered that this type of feedback would take some getting used to. 
Interestingly, all of the participants also manifested that their mastery of the language could be greatly improved through reformulated feedback, since they would be processing their own writings with near-native style.

In addition to the reasons provided by our participants, possible explanations for the more positive effects of EC over REF might relate to the potential differences between the two types of CF provided. First, the very nature of the reformulation process usually entails a high number of modifications, as was the case in our own study: reformulations led to many more changes to the students' original texts than in the error correction condition (52 RFs versus $29 \mathrm{ECs}$ ), which in effect meant that, even though students noticed all the errors in both conditions, the number of REFs they had to remember was much higher than that of ECs. In addition, as noted by Sachs and Polio (2007) in relation to their own data, the greater visual saliency which characterizes error corrections may facilitate uptake. Along the same lines, Sheen (2010b) goes as far as suggesting that explicit CF types "enable learners to notice the gap between their non-target output and the correct form; this, in turn, facilitates interlanguage develoment” (p. 226), However, we would agree with Sachs and Polio that further research is needed before it can be convincingly demonstrated that the degree of perceptual saliency in written CF is a key variable at work in explaining learning outcomes derived from it, further research is needed.

Finally, we cannot disregard possible task effects derived from not having counteracted the order of tasks.

\section{IV.3 Treatment conditions and uptake: type of revisions}

The third main research finding in our study is that our participants performed differently in the two CF treatments regarding the aspects of language that were revised. Our data show that lexis-related revisions appeared to be more amenable to change than grammar or discourse revisions in the reformulation condition, this not being the case in the EC condition. This finding adds further empirical evidence to the task-dependency of the learner's allocation of attentional resources in writing. In this respect, in a review article on the learning potential of writing, Manchón (Forthcoming) concluded that the more open the writing task used in research, the more focus on lexis and the less attention paid to grammar that was observed, although she also noted that these task effects appeared to be mediated by proficiency. She claimed that the closer we get to self-produced writing, the more empirical evidence there is on attention to lexis (and the less attention to grammar). Conversely, the more controlled and grammar-oriented writing tasks and activities are, the more participants have been found to limit to devote their attentional resources to grammar. Our data adds a further piece of the 
puzzle: according to our results, the observed task-dependency in the allocation of attentional resources may also be mediated by the type of feedback that students receive on their writing. As shown in Table 9, the uptake that derived from EC was maintained in the areas of form, lexis, and discourse. In contrast, in the REF condition students incorporated more revisions on lexis. One possible explanation might be that, given the greater amount of total revisions that students were required to process, retain, and incorporate in the REF condition, they prioritized lexical aspects, which is not surprising given the prominence of lexical concerns in all subprocesses of writing: lexical access and retrieval has been found to be crucial during planning, text-generating and revising one’s own text (see Manchón, Roca de Larios \& Murphy, 2007 for a review of research). However, the design of our study did not allow us to confirm these predictions with the participants' own views (we failed to ask questions in this respect in the post-task interviews) or their on-line processing of the feedback received, which would have required some form of protocol data.

\begin{tabular}{|l|l|l|l|l|l|l|l|l|l|}
\hline \multirow{2}{*}{ Treatment } & FORM & \multicolumn{3}{l|}{ LEXIS } & DISCOURSE \\
\cline { 2 - 10 } & Noticed & Incorp. & $(\%)$ & Noticed & Incorp. & $(\%)$ & Noticed & Incorp. & $(\%)$ \\
\hline REF & 20 & 13 & $M=62.5$ & 46 & 35 & $M=75.42$ & 36 & 19 & $M=53$ \\
\hline EC & 34 & 26 & $M=85.71$ & 18 & 15 & $M=87.5$ & 6 & 5 & $M=87.5$ \\
\hline
\end{tabular}

Again, this would be an area worth of further research for theoretical and practical reasons. We mentioned above that Williams (2001) has claimed that "the effectiveness of FonF is ultimately determined by learner need” (pag. 175) and we suggested that the study of writing would be an ideal scenario to investigate these self-generated FonF processes. Our data would justify further inquiry into the way in which the processing of feedback on one's own output fosters attention to which aspects of language, in which conditions, and with what learning effects. Such findings would be illuminating in pedagogical decision-making regarding how to foster language learning through writing.

\section{IV.4 Individual variation in uptake}

Another finding worth discussing relates to the individual quantitative and qualitative differences observed in uptake, a finding that could tentatively be interpreted as suggesting that individual writers may benefit differentially from different forms of written CF, an area in which further research would also be welcome, as noted by Sachs and Polio (2007). A welcome step forward in this respect is a recent study by Storch and Wigglesworth (2010), who concluded from their very rich qualitative data on the processing of two forms of direct 
(error correction) and indirect (editing) written CF by advanced, university ESL learners that a whole set of learner-related factors (including the learners' beliefs, attitudes, and goals) appear to "influence not only the strategies learners adopt in dealing with the feedback received [...] but also their willingness to accept the feedback and the likelihood of retaining it” (p. 328). Our own data would point to the need to expand this research avenue in future studies on CF.

\section{CONCLUSION}

The study presented in this paper has tried to add one more building block to recent attempts to strengthen the interface between SLA and L2 writing research. Despite its exploratory nature, the data obtained can be interpreted as shedding further light on the learning potential associated with writing, in our case in terms of the noticing and uptake that may derive from processing and making use of different forms of written CF, as well as the task-related and learner-variables that may mediate such effects. However, as repeatedly mentioned when reporting our results, these have to be taken with caution given the small sample size, the lack of a control group, and the possible task effects that may have derived from the order in which the tasks were performed.

Despite these limitations, the findings from the study not only expand the empirical data available, but they are also suggestive of further avenues to explore in future. In addition to the various possible lines of research mentioned in the Discussion section, we would argue that the most important item in the future research agenda would be the investigation of the long-term effects on learning of L2 writing, an issue of crucial theoretical relevance in SLA research, and of the utmost pedagogical importance in instructed SLA, particularly in FL contexts given the prominent role that the printed word plays in these contexts and the writing-to-learn purposes that generally characterizes the teaching of writing in these settings. Such a research agenda would entail not only the study of the long-term effects of CF on learning, but also the learning potential that may derive from the very text-generation activity L2 users engage in when they are required to produce challenging written texts in their L2. 


\section{ACKNOWLEDGEMENTS}

The research reported in this article is part of a program of research financed by Fundación Séneca, Centro de Coordinción de Investigción, Research Grant 11942/PHCS/09. We are grateful to the anonymous reviewers for their insightful suggestions on an earlier version of this paper. Any errors that remain are entirely ours.

\section{REFERENCES}

Adams, R. (2003). L2 output, reformulation, and noticing: Implications for interlanguage development. Language Teaching Research, 7(3), 347-376.

Adams, R. \& Ross-Feldman, L. (2008). Does writing influence learner attention to form? In D. Belcher \& A. Hirvela (Eds.), The oral-literate connection. Perspectives on L2 speaking, writing, and other media interactions (pp. 243-266. Ann Arbor: The University of Michigan Press.

Bitchener, J. (2008). Evidence in support of written corrective feedback. Journal of Second Language Writing, 17(2), 102-118.

Bitchener, J. \& Knoch, U. (2008). The value of written corrective feedback in migrant and international students. Language Teaching Research, 12, 409-431.

Leki, I., Cumming, A. \& Silva, T. (2008). A synthesis of research on second language writing in English. New York: Routledge.

Ellis, R., Shenn, Y, Murakami, M. \& Takashima, H. (2008). The effects if focused and unfocused written corrective feedback in an English as a foreign language context. System, 36, 353-371.

Ferris, D. (2010). Second language writing research and written corrective feedback in SLA. Intersections and practical applications. Studies in Second Language Acquisition, 32, 181-201.

Hanaoka, O. (2007). Output, noticing, and learning: An investigation into the role of spontaneous attention to form in a four-stage writing task. Language Teaching Research, 11(4), 459-479.

Lapkin, S., Swain, M. \& Smith, M. (2002). Reformulation and the learning of French pronominal verbs in a Canadian French immersion context. The Modern Language Journal, 86(4), 485-507.

Lázaro, A. (2009). Reformulation and self-correction: Testing the validity of correction strategies in the classroom. RESLA, 22, 189-215.

Leow, R. P. 2000. A study of the role of awareness in foreign language behavior. Studies in Second Language Acquisition, 22, 557-584.

Manchón, R.M. (In press a). The language learning potential of writing in foreign language contexts. Lessons from research. In M. Reichelt \& T. Chimasko (Eds.), Foreign language writing. Research insights. West Lafayette: Parlour Press.

Manchón, R.M. (In press b). Teaching writing. The encyclopedia of applied linguistics. New York: Wiley-Blackwell.

Manchón, R.M. (Forthcoming). Writing to learn the language. Issues in theory and research. In R.M. Manchón (Ed.), Learning to write and writing to learn in an additional language. Amsterdam: John Benjamins.

Manchón, R.M. \& Roca, J. (Forthcoming). Writing to learn in FL contexts: Learners' perceptions of the language learning potential of L2 writing. In R.M. Manchón (Ed). Learning to write and writing to learn in an additional language. Amsterdam: John Benjamins.

Nassaji, H. \& Swain, M. 2000. A Vygotskian perspective on corrective feedback in L2: The effect of random versus negotiated help on the learning of English articles. Language Awareness, 9(1), 34-51.

Niu, R. 2009. Effect of task-inherent production modes on EFL learners' focus on form. Language Awareness, 18(3-4), 384-402.

Ortega, L. (2009). Studying writing across English as a foreign language contexts: Looking back and moving forward. In R. M. Manchón (Ed.), Writing in foreign language contexts: Learning, teaching, and research (pp. 232-255). Clevedon, UK: Multilingual Matters. 
Qi, D. S. \& Lapkin, S. 2001. Exploring the role of noticing in a three-stage second language writing task. Journal of Second Language Writing, 10(4), 277-303.

Robinson, P. 1995. Attention, memory and the "noticing" hypothesis. Language Learning, 45, 283331.

Rosa, E. \& O’Neill, M. 1999. Explicitness, intake, and the issue of awareness. Another piece of the puzzle. Studies in Second Language Acquisition, 21, 511-556.

Sachs, R. \& Polio, C. 2007. Learners' uses of two types of written feedback on an L2 writing revision task. Studies in Second Language Acquisition, 29, 67-100.

Schmidt, R. W. 1990. The role of consciousness in second language learning. Applied Linguistics, 11, 206-226.

Schmidt, R. W. (1993). Awareness and second language acquisition. Annual Review of Applied Linguistics, 13, 11-26.

Schmidt, R. 2001. Attention. In P. Robinson (Ed.), Cognition and second language instruction (pp. 332). Cambridge: Cambridge University Press.

Sheen, Y. 2007. The effect of focused written corrective feedback and language aptitude on ESL learners' acquisition of articles. TESOL Quarterly, 4,255-283.

Sheen, Y. (2010a). The role of oral and written corrective feedback on SLA. Studies in Second Language Acquisition, 32, 169-179.

Sheen, Y. (2010b). Differential effects of oral and written corrective feedback in the ESL classroom. Studies in Second Language Acquisition, 32, 203-234.

Storch, N. (2002a). Relationships formed in dyadic interaction and opportunity for learning. International Journal of Educational Research, 37, 305-322.

Storch, N. (2002b). Patterns of interaction in ESL pair work. Language Learning, 52(1), 119-158.

Storch, N. (2007). Investigating the merits of pair work on a text editing task in ESL classes. Language Teaching Research, 11(2), 143-159.

Storch, N. 2009. Metatalk in a pair work activity: Level of engagement and implications for language development. Language Awareness, 17(2), 95-114.

Storch, N. \& Wiglesworth, G. (2010). Learners' processing, uptake, and retention of corrective feedback on writing. Studies in Second Language Acquisition, 32, 303-334.

Suzuki, W. (2008). The effect of written languaging combined with feedback on second language writing. Paper presented at the AAAL 2008 Annual Conference, Washington, DC, March.

Swain, M. (1985). Communicative competence: Some roles of comprehensible input and comprehensible output in its development. In S. Gass \& C. Madden (Eds.), Input in second language acquisition (pp. 235-153). Rowley, Mass.: Newbury House.

Swain M. (1995). Three functions of output in second language learning. In G. Cook \& B. Seidlhofer (Eds.), Applied linguistics. Studies in honour of H. G. Widdowson (pp. 125-144). Oxford: Oxford University Press.

Swain, M. (1998). Focus on form through conscious reflection. In C. Doughty \& J. Williams (Eds.), Focus on form in classroom second language acquisition (pp. 64-81). Cambridge: Cambridge University Press.

Swain, M. 2000. The output hypotheses and beyond: Mediating acquisition through collaborative dialogue. In J. Lantolf (Ed.), Sociocultural theory and second language learning (pp. 97-114). Oxford: Oxford University Press.

Swain, M. \& Lapkin, S. (1998). Interaction and second language learning: Two adolescent French immersion students working together. The Modern Language Journal, 82(3), 329-337.

Swain, M. \& Lapkin, S. (2002). Talking it through: Two French immersion learners' response to reformulation. International Journal of Educational Research, 37, 85-304.

Thornbury, S. (1997). Reformulation and reconstruction: Tasks that promote "noticing”. ELT Journal, 51, 326-335.

Tocalli-Beller, A. \& Swain. M. 2005. Reformulation: The cognitive conflict and L2 learning it generates. International Journal of Applied Linguistics, 15(1), 5-28.

Tomlin, R. S. \& Villa, V. 1994. Attention in cognitive science and second language acquisition. Studies in Second Language Acquisition, 16, 183-203.

Toth P. D. 2006. Processing instruction and a role for output in second language acquisition. Language Learning, 56(2), 319-85. 
Watanabe, Y. \& Swain, M. 2007. Effect of proficiency differences and patterns of pair interaction on second language learning: collaborative dialogue between adult ESL learners. Language Teaching Research, 11(2), 121-142.

Williams, J. (2001). Learner-generated attention to form. In R. Ellis (Ed.), Form-focused instruction and second language learning (pp. 303-346). Malden, MA: Blackwell.

Williams, J. (2008). The speaking-writing connection in second language and academic literacy development. In D. Belcher and A. Hirvela (Eds.), The oral/literate connection: Perspectives on L2 speaking, writing, and other media interactions (pp. 10-25). Ann Arbor, MI: University of Michigan Press.

$\mathrm{Xu}, \mathrm{C}$. (2009). Overgeneralization from a narrow focus: A response to Ellis et al. (2008) and Bitchener (2008). Journal of Second Language Writing, 18(4), 270-275. 